\title{
Sitting and silent meditation as a strategy to study emotion regulation
}

\author{
Carolina B. Menezes, Mirtes G. Pereira and Lisiane Bizarro \\ Universidade Federal do Rio Grande do Sul, Porto Alegre, RS, Brazil
}

\begin{abstract}
Emotion regulation is the capacity to control the way in which people attend, perceive, process and react to emotional information. Practitioners of sitting and silent meditation develop a greater control of their mental processes, culminating in regulatory abilities that lead to well-being and emotional balance. In this paper we reviewed evidence from recent studies on neurophysiology and cognitive psychology on emotion regulation - focusing on negative emotions - and meditation in order to discuss their intertwining. This critical review showed that controlling attention and fostering a relaxation state are the main mechanisms for the interaction between emotion regulation and meditation. Importantly, it is suggested that the effects of meditation on emotion regulation should be conceptualized separately as those taking effect during the practice and those occurring as an outcome of such practice. Finally, it is highlighted that meditation should be conceived as a particular type of emotion regulation strategy, and that further studies comparing these strategies more directly are warranted. Keywords: emotion regulation; meditation, attention, relaxation.
\end{abstract}

Received 4 May 2012; received in revised form 12 June 2012; accepted 14 June 2012. Available online 29 June 2012.

\section{Introduction}

Emotions permeate human life in almost every instant. From relationships that characterize social life such as family, friends, colleagues, partners, and even contact with strangers to the various choices one has to make throughout their lifespan, e.g., profession, leisure, development of skills or life style. The way we approach, think and act in each of these contexts may depend on how we regulate emotions.

One of the interests of psychologists is to investigate the human capacity to control the way in which people attend, perceive, process and react to emotional information. It is discussed that this control can be understood as emotion regulation. One practice that has been gaining attention concerning its regulatory role is the sitting and silent meditation. The aim of this paper is to describe emotion regulation-focusing on negative emotions such as fear, anger, disgust, sadness-and meditation from a cognitive point of view and, based on this perspective, discuss their relationship. It is proposed

Carolina B. Menezes and Lisiane Bizarro, Laboratory of Experimental Psychology, Neuroscience and Behavior, Institute of Psychology, Federal University of Rio Grande do Sul, Porto Alegre, RS, Brazil. Mirtes G. Pereira, Laboratory of Behavioral Neurophysiology, Biomedical Institute, Federal University of Fluminense, Niterói, RJ, Brazil. Correspondence regarding this article should be directed to: Carolina B. Menezes, Rua Ramiro Barcelos, 2600, sala 105, Faculdade de Psicologia, UFRGS, Porto Alegre, RS, 90035-003, Brazil. Phone: +55 5133085363. E-mail: menezescarolina@hotmail.com that controlling attention and fostering a relaxation state are the main mechanisms for this interaction, and that meditation should be conceived as a particular type of emotion regulation strategy.

\section{Emotion Regulation}

Emotion regulation refers to the ability of modulating one or a set of emotions, i.e., the capacity to control and influence which emotions we feel, when we feel them, and how we experience and express them (Gross, 1998). In the perspective of affective and cognitive neuroscience, the modulation of emotion involves changes in emotional processing through its interaction with cognitive processes and the plasticity of underlying circuitries (Davidson, Jackson, \& Kalin, 2000). Even though these definitions encompass positive and negative emotions, in this paper we focus on the regulation of negative emotions.

In spite of divergent opinions (Panksepp, 2003), there has been an increase in the attempt to conceive emotion and cognition as interdependent, based on the idea that many neural circuits seem to overlap across these functions (Davidson, 2003; Pessoa, 2008; Phelps, 2006). Even though this relationship can be studied in various contexts such as emotional learning, memory, attention and perception, processing of social stimuli, cognitive change of emotional responses, among others (Phelps, 2006), the focus of this paper is on the cognitive control of emotion, also known as emotion regulation. Despite discussion that this regulation can be either 
voluntary or automatic (Gyurak, Gross, \& Etkin, 2011), most studies usually focus on the deliberate control of emotion, also referred to as top-down control, downregulation, or hot control, which can influence the generation of an emotion (Ochsner et al., 2009) or an ongoing emotion (Ochsner et al., 2004).

Two main cognitive theories have established the tenets for understanding the cognitive control of emotion: appraisal theory and information processing approach (Scherer, 2003). The first advocates that every emotion depends on the subjective evaluation one makes of the relevance of different situations, which can be immediate, imagined or recalled, and how this relates to one's needs and goals (Ellsworth \& Scherer, 2003). In other words, emotions result from the appraisal people make when they contrast and interpret internal and external cues. According to the second theory, understanding of mental processing is based on the idea of a hierarchical organization. Accordingly, attention allocation is considered one of the main indicators of resource allocation to cognitive processing of all types of stimuli including emotional ones (Dalgleish, 2003).

More recently, these theories have been integrated in a broader, well-established model of emotion regulation where reappraisal and attention allocation are some of the strategies that can be used along a continuum, occurring before or after the emotion onset (Gross, 1998; 2002). According to this model, emotion regulation strategies used before emotion generation are called antecedent strategies or cognitive strategies and include situation selection, situation modification, selective attention, attentional distraction, and cognitive reappraisal. The emotion regulation strategy that occurs after emotion onset is referred to as suppression, being considered a behavioral strategy because it is focused on the ongoing emotional response.

There is some evidence corroborating the proposition of a temporal distinction between cognitive strategies - thought to impact the early emotiongenerative process - and behavioral strategies, thought to exert some control at a later generative stage. Through the use of fMRI, the effects of reappraisal and suppression during a negative eliciting film were compared. Earlier activation (0-4.5 sec.) of prefrontal cortex regions was observed during reappraisal strategies compared to later activation $(10.5-15 \mathrm{sec})$ for behavioral suppression (Goldin, McRae, Ramel, $\&$ Gross, 2008). Despite this empirical evidence for a temporal distinction, it is discussed that the contexts in which the strategies may be used can vary. Therefore, cognitive strategies can also be applied after emotion onset, during its course. This process has been coined online regulation (Sheppes \& Meiran, 2007).

\section{Similar and distinct effects of emotion regulation strategies}

Evidence shows that different strategies can influence emotional processing and, depending on their type, timing and context, can have similar or distinct effects, which can manifest through different domains and/or their interplay such as behavioral, experiential, and physiological (Gross, 2002). Three commonly studied strategies are 1) reappraisal-changing the interpretation of an emotionally evocative stimulus, 2) distraction-changing attentional focus in order to limit attention to emotional stimuli, and 3) suppressioninhibiting prepotent emotional responses, all of which show significant results in the reduction of negative emotional experience (Goldin et al., 2008; McRae et al., 2010; Sheppes \& Meiran, 2007). However, when compared, reappraisal seems to be more effective than distraction and suppression in reducing this experience in an antecedent manner (Goldin et al., 2008; McRae et al., 2010), but suppression seems more effective for reducing facial expressive behavior (Goldin et al., 2008). As for distraction, compared to reappraisal, more significant reductions in emotional experience and skin conductance responses are observed when the regulation is online (Sheppes, Catran, \& Meiran, 2009; Sheppes \& Meiran, 2007).

In accordance with these results, a greater activation of regions implicated in the control of cognition and emotion during the use of some of these strategies is also observed compared to others. Reappraisal has been associated with activation of medial, dorsolateral, ventrolateral, ventromedial prefrontal cortices, lateral orbitofrontal cortex, and anterior cingulate cortex (Goldin et al., 2008; Kompus, Hugdahl, Öhman, Marklund, \& Nyberg, 2009; McRae et al., 2010; Ochsner, Bunge, Gross, \& Gabrieli, 2002; Ochsner \& Gross, 2005) and with the modulation of amygdala, insula and medial orbitofrontal cortex (Goldin et al., 2008; McRae et al., 2010; Ochsner et al., 2002; van Reekum et al., 2007). Thus, prefrontal regions that are related to cognitive deliberate control, such as the amygdalae, may exert inhibitory control of crucial structures for the generation and expression of emotions (Lobo et al., 2011; Ochsner et al., 2002; Ochsner \& Gross, 2005; Ray, Ochsner, Cooper, Robertson, Gabrieli, \& Gross, 2005)

Similar patterns are found for suppression and distraction, but with some differences. In comparison to suppression, reappraisal strategy produced a greater deactivation of amygdala and insula (Goldin et al., 2008), which suggests a more effective modulation of emotion generation. On the other hand, distraction, when compared to reappraisal, showed a more significant reduction in the activity of amygdala as well as greater increases in right lateral prefrontal cortex and bilateral clusters in superior parietal cortex, which are associated with selective attention (McRae et al., 2010). Conversely, in comparison to distraction, reappraisal showed a greater activation of dorsomedial prefrontal cortex, bilateral dorsal and ventrolateral prefrontal cortex, regions believed to underlie the processing of affective meaning when facing one's current goals (Van Overwalle, 2008). Moreover, only in reappraisal did some of these regions report a correlation with 
decreased negative affect, indicating that this strategy may be more effective in down-regulating emotional experience (McRae et al., 2010).

Noteworthy, activation of ventromedial prefrontal cortex and anterior cingulate cortex, and hypoactivation of amygdala seem to be of particular importance to the regulation process, especially concerning fear. These are the regions that have been found to overlap when comparing different forms of regulation such as fear extinction, placebo, and cognitive emotion regulation (Delgado, Nearing, LeDoux, \& Phelps, 2008; Diekhof, Geier, Falkai, \& Gruber, 2011; Kompus, et al., 2009). In line with these results, some authors discuss that the observed mutual changes in functional activity of dorsolateral prefrontal cortex and amygdala in emotion regulation, despite evidence of no direct connections between these regions, may be explained if one considers a mediating role for ventromedial prefrontal cortex, once this region connects to the other two (Delgado et al., 2008).

Even though these results may indicate a brain network related to the regulation of negative emotions, it is not yet clear to what extent these results may be generalized. The studies described above differed in terms of the kind of stimuli (e.g., faces, complex scenes or film clips) used to evoke emotion and the category of emotion (e.g., fear, disgust, sadness, anger). Therefore, studies using the same methodology, but varying only the emotional variable on which the regulatory strategy is being applied to, should be carried out to help disentangle possible particularities.

\section{A special note on attention}

Despite the theoretical classification and differentiation of strategies such as reappraisal, attention allocation and suppression and the empirical evidence that gives it support, one discussion concerning the use of these strategies relates to how much they interact. In this regard, some authors question whether control of attention allocation could be a fundamental part of every regulation process through fundamental inhibitory processes (Thayer \& Lane, 2000), constituting the basis on which reappraisal builds up (van Reekum et al., 2007). One study that attempted to test this hypothesis found that gaze fixation as an index of visual attention accounted for a significant amount of variance in almost all clusters of frontal regions activated during a reappraisal strategy, a condition in which participants spent significantly less time fixating at the picture and its relevant parts (van Reekum et al., 2007), although this result has not been replicated with other measures (Urry, 2010). In support of the key role of attention in emotion regulation, another study found that attention influenced an earlier stage of the emotion-generative trajectory in comparison to reappraisal (Thiruchselvam, Blechert, Sheppes, Rydstrom, $\&$ Gross, 2011). This is in accordance with information processing approaches, which posit that attention is fundamental for the selection of information and guidance of behavior (Dalgleish, 2003).
Studies interested in the role of attention for the emotion regulation process try to investigate whether varying attentional demands can differently modulate the interference of emotion, despite evidence of the automaticity of emotion (Anderson, 2005; Hodsoll, Viding, \& Lavie, 2011; Vuilleumier, 2005). For this purpose, investigators manipulate not only the gaze, but the aspects one has to orient attention to and decide upon (Erthal et al., 2005; Lavie, Ro, \& Russell, 2003; Mitchell et al., 2007; Pessoa, Padmala, \& Morland, 2005; Silvert et al., 2007; Vuilleumier et al., 2001). Even though results diverge, most indicate that attention can be important for emotion modulation. In some cases, emotional/social stimuli were effectively modulated (Silvert et al., 2007; Stein, Peelen, Funk, \& Seidl, 2007), and in some cases not (Lavie et al., 2003; Vuilleumier et al., 2001). Sometimes the modulation was detected only in the cerebral but not in the behavioral response (Mitchell et al., 2007; Pessoa et al., 2005).

The potential of attention allocation for emotion regulation has influenced the development of interventions that use this strategy as its core technique (for a review, see Wadlinger \& Isaacowitz, 2011). From a cognitive perspective, some believe that mental illnesses derive from a maladaptive cognitive processing, which is characterized by a pattern of inflexible and self-focused, ruminative attention (Wells, 2006) or a tendency for attentional bias towards the impairing stimuli (Dalgleish, 2003). The SelfRegulatory Executive Function Model, for example, understands that emotional disorders result from this persistent pattern of negative thinking and attention allocation (Wells, 2009). Accordingly, for controlling this cognitive style, it is suggested that one needs to develop metacognitive modes of operation, which can be achieved by attention training such as selective attention, attention switching and divided attention. Through this executive control, people should learn to more easily develop new information-processing routines, viewing unwanted thoughts in a non-self-relevant and nonthreatening way. There is evidence, for instance, that an 8-week psychotherapeutic intervention based on this model (Wells, 2006) promoted improvements in persons with Generalized Anxiety Disorder as indicated by significantly reduced scores on the Trait Anxiety Subscale and Beck Anxiety Inventory (Wells, 2009).

Other interventions used behavioral tasks for training attention such as the Dot-Probe Task in which individuals learn to bias their attention differently, e.g., by disengaging faster from negative cues and reorienting their attention to neutral or positive ones (Wadlinger \& Isaacowitz, 2008). It should be noted that in these experiments, it is often unknown whether this skill transfers to more ecological contexts and how long the effects last. However, a recent meta-analysis showed that this type of intervention can indeed be effective for treatments such as anxiety disorders (Hakamata et al., 2010).

To some authors, however, there should be a distinction between the type of training involved in the 
Dot-Probe Task (Wadlinger \& Isaacowitz, 2008) referred to as attention training and what they coined as attention state training (Tang \& Posner, 2009). According to this distinction, in the first type the aim is to develop executive attention networks, directed attention and effortful control. The second should be characterized by effortless control, training of autonomic systems and a state of balance and calmness which, contrary to the first type, should not generate fatigue (Tang \& Posner, 2009). As examples of these trainings, the authors cite video games and some eastern practices, respectively. Sitting and silent meditation is an eastern practice that, according to this distinction, involves attention state training and that has been increasingly investigated, especially in relation to its influence on emotion regulation (Wadlinger \& Isaacowitz, 2011).

\section{Sitting and Silent Meditation}

Despite being originally related to eastern philosophies, sitting and silent meditation has become a mainstream subject of scientific interest in the west. In this context, it has been described as a form of mental training through which practitioners try do develop a greater control of their mental processes, culminating in regulatory abilities that lead to the cultivation of well-being and emotional balance. In psychological terms, this type of mental training may promote a less conditioned awareness, which facilitates the decentering and de-identification with dysfunctional mental processes such as rumination (Walsh \& Shapiro, 2006). In meditation traditions, as well as in cognitive psychology, a core underlying concept is that the way one relates to his/her interpretation of facts is more relevant than the facts themselves (Teasdale, 1999). Hence, a lessconditioned awareness would result in less automatic interpretations and this would be related to greater mental health and well-being.

Based on contemplative practices and theories as well as their psychological secular adaptations, this type of meditation has been classified-according to a westernized operational definition - into two main styles of practice known as focused attention (FA) and open monitoring $(\mathrm{OM})$ meditation. In the first one there is a voluntary and sustained focusing of attention on a chosen object. In the second, subjects train to monitor the content of experience moment by moment in a nonreactive, nonjudgmental way, thus not engaging in any of the emergent contents (Lutz, Slagter, Dunne, \& Davidson, 2008).

It should be noted that this division has been greatly influenced by Buddhist practices in that two types of meditations that originally come from this traditionshamatha and vipassana - are often used as examples for FA and OM, respectively (Lutz, Dunne, \& Davidson, 2007; Lutz, Slagter, Dunne, \& Davidson, 2008). To some authors, however, it is important to highlight that these definitions and some discussions surrounding them should be considered westernized adaptations that do not fully correspond to the original meanings and depth of the ancient practices such as the Buddhist ones already mentioned or the two main types derived from the Yoga tradition, namely, dharana and dhyana (Telles, Naveen, \& Balkrishna, 2010). We recommend other readings for a theoretical and philosophical review, which is not the aim of the present work (for a discussion on the Buddhist and Yoga perspective, respectively, see Siegel, Germer, \& Olendzki, 2009; Telles et al., 2010).

Such definitions and operationalizations are still an ongoing debate and the scientific study of meditation is recent. Thus, more theoretical and empirical studies are warranted. In light of this, and due to the fact that a great amount of empirical psychological research is based on FA and OM meditations, the present article will review papers that investigated these types as well as dharana, given its similarity to FA (Telles et al., 2010). It should be noted, however, that these are broad classifications that encompass different types of meditation. Nevertheless, according to these classifications, different styles share common features according to the category they pertain to. Therefore, for the purpose of the present article, we will rely only on the broader terms to refer to sitting and silent meditation. Another reason for including these is that many meditation-based interventions that have been increasingly used and tested concerning their role on emotion regulation include mindfulness meditation (Baer, 2006). This is a more secular, westernized practice that falls under OM category (Lutz et al., 2008).

During practice, FA and OM types can interact and some argue that, for both styles, controlling the allocation of attention is a key part of the process. Accordingly, it is suggested that without the ability to sustain attention, one cannot control reactivity to external and internal distractions or the vigilance of one's own awareness (Wallace, 2008; Wallace \& Shapiro, 2006). Given that attention can influence early stages of emotion-generative trajectory (Thiruchselvam et al., 2011), meditation from a cognitive perspective could be a tool for developing emotion regulation skills.

Many studies have already demonstrated that meditation can improve attentional skills (for a review, see Lutz et al., 2008). Results have shown improvement in sustained attention (Chambers, Yee Lo, \& Allen, 2008; Jha, Krompinger, \& Baime, 2007; MacLean et al., 2010), executive attention (Tang et al., 2007), and working memory (Zeidan, Johnson, Diamond, David, \& Goolkasian, 2010). Neurophysiological measures along with behavioral tasks provided evidence for the hypothesis that attention is improved because, through meditation, practitioners learn to distribute their mental resources, which are limited, more efficiently (Slagter et al., 2007).

A similar conclusion has been made based on the finding that a better perceptual sensitivity was related to an improved vigilance capacity in meditators (MacLean et al., 2010). The authors discuss that perceptual improvements may reduce the resource demand necessary for the target discrimination, making it more available and, therefore, easier to sustain attention 
voluntarily. Likewise, other studies show that meditators can have a greater capacity to control their engagement in the processing of irrelevant distractors (Cahn \& Polich, 2009; Kumar, Nagendra, Naveen, Manjunath, \& Telles, 2010; van den Hurk, Janssen, Giommi, Barendregt, \& Gielen, 2010) or to more easily disengage from them (Hasenkamp, Wilson-Mendenhall, Duncan, \& Barsalou, 2012; Pagnoni, Cekic, \& Guo, 2008). Hence, controlling the processing of interferences could be one possible explanation why meditators can better distribute their resources and dose their expenditure, and this may be due to attentional inhibitory control.

Another main feature of meditation practice is the ability to achieve a balance between an alert and a relaxed state of mind and body (Wallace, 2008). In line with this, some studies show a decrease in physiological arousal during meditation (Danucalov, Simões, Kozasa, \& Leite, 2008; Telles, Mohapatra, \& Naveen, 2005) and a concomitant effect of a relaxed state with an attentive mind during practice (Kubota et al., 2001; Takahashi et al., 2005; Tang et al., 2009). This can be particularly important because some studies demonstrated that high levels of anxiety can interact with attention, impairing the cognitive modulation of negative emotion (Johnson, 2009; Mocaiber et al., 2009).

Therefore, combining the ability to produce an alert and relaxed mind/body state may be very helpful for emotion regulation, and this is precisely what meditation is believed to foster (Lutz et al., 2007). Next, we present a review of studies that more directly evaluated the effect of meditation on emotion regulation. Importantly, some authors recently pointed out that a clearer distinction should be made between studies that investigate the outcomes of regulatory processes or the regulatory process itself (Wadlinger \& Isaacowitz, 2011). Therefore, meditation results will be divided into effects that occur as an outcome of the training and those that happen during the practice.

\section{Meditation and Emotion Regulation: Outcomes of meditation training}

Results are sometimes divergent (Arch \& Craske, 2006; Erisman \& Roemer, 2010; Jain et al., 2007; Kingston, Chadwicka, Meronc, \& Skinnera, 2007), although many seem to converge, showing a positive effect of the practice on affective processes (Arch \& Craske, 2006; Jain et al., 2007; Klatt, Buckworth, \& Malarkey, 2009; Leite et al., 2010). For example, it has been demonstrated that meditating for 15 min after exposure to negative images generated a reduction in negative affect and an increased tolerance to watch the images in comparison to controls (Arch \& Craske, 2006). However, this effect has not been found after $10 \mathrm{~min}$ of meditation following exposure to a sad film (Erisman \& Roemer, 2010). The difference on the outcomes of these studies may be due to the fact that the study of Arch and Craske (2006) compared meditation with a worrying condition, whereas the study of Erisman and Roemer
(2010) used passive viewing as comparison. For such a brief intervention in meditation-naïve participants, one may hypothesize that the effect of the state of meditation is more effective in regulating emotion in comparison to a maladaptive strategy such as worrying, but not in comparison to a neutral strategy. However, it should be noted that both studies did find a greater reduction in negative affect in the meditation group when compared to passive viewing, but the difference did not reach significance. Thus, another possible explanation is that there was no sample power to reveal the expected results.

Some discrepancies were also found in other studies using 3- (Kingston et al., 2007) or 4-week interventions (Jain et al., 2007). Jain et al. (2007) did find significant reductions in stress, whereas Kingston et al. (2007) found no evidence that meditation produced a difference in negative affect outcome. Again, differences in experimental paradigm may explain the divergence because the amount of meditation required varied in these studies.

Positive results such as decreased depression and stress have also been observed in a 5-week (Leite et al., 2010) and 6-week intervention (Klatt et al., 2009), respectively, corroborating the findings described by Jain et al. (2007). For longer interventions such as 8 weeks, there has been evidence for a reduction in negative affect (Davidson et al., 2003; Jha, Stanley, Kiyonaga, Wong, \& Gelfand, 2010; Schroevers \& Brandsma, 2010) and reductions in anxiety (Chiesa \& Serretti, 2009; Davidson et al., 2003; Fang et al., 2010; Farb et al., 2010; Goldin \& Gross, 2010), depression (Farb et al., 2010; Goldin \& Gross, 2010), and stress scores (Chiesa \& Serretti, 2009; Fang et al., 2010; Shapiro, Oman, Thoresen, Plante, \& Flinders, 2008). Along the same lines, interventions lasting 3 months similarly demonstrated more positive psychological functioning such as reduced stress, anxiety and difficulty in emotion regulation (Jacobs et al., 2011; Sahdra et al., 2011).

Interestingly, better psychological outcomes seem to positively influence immunological parameters in practitioners. Participants who showed a reduction in stress and increase in well-being after an 8-week mindfulness training, contrary to subjects who did not show these improvements, presented increased natural killer cell activity and decreased C-reactive protein level, which are markers of systemic immune function that characterize, respectively, nonspecific cellmediated cytotoxicity and inflammation (Fang et al., 2010). Similarly, a 3-month intervention in comparison to a control group produced an increased telomerase activity - a predictor of long-term cellular viabilitywhich was mediated by higher scores in perceived control and lower scores in neuroticism (Jacobs et al., 2011). These results underscore the importance of emotion regulation for psychological and physical health and the usefulness of meditation to achieve this.

Moreover, some of the psychological outcomes so far mentioned seem to be influenced by improvements 
in attention regulation (Sahdra et al., 2011), working memory (Jha et al., 2010), and mindfulness (Jacobs et al., 2011; Leite et al., 2010; Schroevers \& Brandsma, 2010), whose construct encompasses attention and awareness. These findings corroborate the discussion on the role of attention for emotion regulation (van Reekum et al., 2007) and how this may apply to meditation practice.

Consistent with this are the results from an experiment that evaluated meditation effects with a behavioral task measuring the interference of emotional images in an attentional task. After an 8-week training session, meditators suffered less interference from unpleasant images as indexed by shorter time reactions and skin conductance response in comparison to a relaxation and wait-list control group. Additionally, only in the meditation group was there a significant reduction in the intensity of negative feeling, according to a self-assessment rating scale (Ortner, Kilner, \& Zelazo, 2007). Authors interpreted that meditation may develop a greater capacity of interrupting the processing of negative stimuli, therefore making more resources available for a more efficient performance on the attentional task. These results agree with a previous study that evaluated meditators (varying between 5 and 10 years of practice experience) and control EEG activity when exposed to an emotional arousing film clip (Aftanas \& Golosheykin, 2005). Only controls showed an increase in gamma synchronization, indicating that they manifested more reactivity to the emotion induction. This was supported by a higher rating of emotional feelings in response to the film in this group.

It should be noted that the number of studies is still small, but very few have reported no effect (Erisman $\&$ Roemer, 2010; Kingston et al., 2007). Nevertheless, methodological variability is large, especially concerning the dependent variables, and results should be interpreted with caution.

\section{Meditation and Emotion Regulation: The practice as a regulatory process}

Other studies evaluated the effects of meditation on emotion regulation as the practice happens. For example, Taylor et al. (2011) examined whether practicing mindfulness while being exposed to emotional and neutral pictures would produce distinct effects compared to passive viewing of the images. For each of these conditions, experienced (ranging from 1,000-3,000 h of practice) and novice (instructed to practice for $20 \mathrm{~min}$ for 7 days prior to the experiment) practitioners were tested. Compared to passive viewing, both experienced and novice meditators showed a decrease in the evaluation of intensity for the valenced pictures. Importantly, they seem to rely on distinct neural networks to obtain emotional modulation. Experienced meditators showed a deactivation of regions involved in the default mode of operation-medial prefrontal cortex and posterior cingulated cortex - but no difference on the activation of amygdala, whereas novices showed an increased activity of superior medial frontal gyrus and reduced activity of the left amygdala. The authors interpreted the pattern observed in experienced practitioners as indicative of an ability to accept and experience the elicited emotion, but without engaging in its content, i.e., without associative or self-referential thoughts interference (Taylor et al., 2011). This corroborates the idea that one main ability that is developed with mindfulness meditation is acceptance and nonjudgement of stimuli (Bishop et al., 2004). This result also indicates that mindfulness may constitute an alternative form of regulation. Taylor et al. (2011) further discussed that novices, on the other hand, could also regulate emotion but in a more typical top-down fashion, probably using more effortful control for the process. Together these results are particularly interesting because they show that novices, in this case with a 1-week experience, can already benefit from mindfulness as a form of emotion regulation and that expertise could provide further and more specific abilities in this respect.

Other studies also found a reduction of default mode regions when mindfulness (Farb et al., 2010; Farb et al., 2007) and FA meditation (Brefczynski-Lewis et al., 2007) were used to regulate interference from emotional stimuli. In these studies, experience of mediators included, respectively, an 8-week training and between 19,000 and $44,000 \mathrm{~h}$. Therefore, not engaging in selfreferential processes seems to be a possible mechanism by which meditation helps regulating emotion.

It has been suggested that not engaging in selfreferential processing, in turn, may be facilitated by greater interoceptive and somatic awareness. This was hypothesized given the observation that, during the use of meditation to regulate interference from emotional distractors, there was greater activation of regions involved in this type of awareness such as the insula and somatosensory areas (Farb et al., 2010; Farb et al., 2007).

However, this finding varies according to the method used. For instance, one type of behavioral assessmentheartbeat detection task - has not been able to demonstrate interoceptive awareness in meditators with a minimum of 15 years of practice (Khalsa et al., 2008), contrary to the results found by Sze, Gyurak, Yuan and Levenson (2010). These authors evaluated coherence- the synchronization of different response systems such as behavioral and physiological during an emotion-while meditators with an average practice of 7 years, professional dancers, and inactive controls were exposed to an emotional film. Meditators had greater coherence between second by second averages of subjective emotional experience ratings - obtained through affect rating dial, and heart periods - the time interval between successive R-waves on the EKG. In addition, significantly higher visceral awareness was reported by meditators compared to the other two groups (Sze et al., 2010). Accordingly, body cues and body awareness may play a fundamental role in evaluation and decision processes (Damasio, 1996); hence, this may be an important component of emotion regulation. 
An important distinction is that a higher visceral awareness does not necessarily mean more reactivity to body sensations. In fact, Perlman, Salomons, Davidson and Lutz (2010) showed that during mindfulness meditation, compared to a control group, long-term practitioners - minimum of $10,000 \mathrm{~h}$ of practicereported less unpleasantness for painful stimuli even though there was no difference for intensity rating. Therefore, practitioners were aware of the pain intensity but manifested reduced cognitive elaboration of the sensory experience (Perlman et al., 2010).

Meditation may also help emotion regulation in specific disorders such as social anxiety. After participating in an 8-week mindfulness training period, subjects suffering from this disorder were instructed to react normally, meditate or use a distraction strategy while being exposed to social anxiety self-beliefs. After the intervention, the ratings of self-belief intensity were significantly lower in the meditation condition. Moreover, there was a significant reduction in activation of the amygdala as well as an increased activity in visual attentional areas such as inferior and superior parietal lobule, cuneus, precuneus, and middle occipital gyrus (Goldin \& Gross, 2010). It was hypothesized that this brain pattern indicated that, despite the fact that participants oriented their attention to the self-beliefs and, therefore, controlled their avoidance of such stimuli (a clinical symptom of such disorder), they were also less reactive to them, given the reduced amygdala activity. Not ignoring the stimulus, but not necessarily engaging in its emotional processing, corroborates the idea that meditation fosters acceptance (Bishop et al., 2004) along with the ability to control the processing of distractions and interferences, even when they are emotional (Aftanas \& Golosheykin, 2005; Ortner et al., 2007; Perlman et al., 2010; Taylor et al., 2011).

\section{Meditation as a particular strategy of emotion regulation}

Results indicate the usefulness of meditation training for the development of regulatory skills for negative emotions. Importantly, meditation seems to characterize a particular type of strategy, eliciting different patterns compared to those strategies commonly investigated, namely, reappraisal and attention deployment.

Reappraisal involves the intentional reinterpretation of emotional stimuli, activation of areas related to self-referential processing and processing of affective meaning (Ochsner \& Gross, 2005). Through meditation, on the other hand, practitioners develop the ability to modulate reactivity, but controlling their engagement in self-referential processing (Taylor et al., 2011). Therefore, meditation may help in changing the way practitioners relate to their interpretations rather than the interpretations per se (Teasdale, 1999).

In comparison to attention deployment strategies such as distraction, meditation seems to be more efficient in implementing attentional resources and modifying automatic reactivity in the context of negative cues (Goldin \& Gross, 2010). Still concerning distraction, it has been found that even though its regulatory impact on negative stimuli takes effect faster than reappraisal, people who use distraction are more reactive to these stimuli when subsequently presented to them (Thiruchselvam et al., 2011). This was interpreted as indicating that distraction may only be useful as a momentary regulation without lasting effects. A reasonable expectation because meditation seems to foster nonavoidance of stimuli, but acceptance without engagement in its processing, is that it probably produces long-term results, irrespective of whether the stimulus is being presented for the first time or repeatedly. Finally, meditation may differ from reappraisal and distraction because practitioners learn to interrupt or diminish these appraisals in the first place, precluding the need for reinterpretation or of avoiding the stimulus by a momentary distraction technique. Noteworthy, such skills may be particularly relevant for coping with automatic biased cognitions that characterize different disorders such as posttraumatic stress disorder, phobias, obsessive compulsive disorder, and depression, among others.

We hypothesized (Figure 1) that these meditation skills result from the efficiency in controlling one's focus of attention (van Reekum et al., 2007) through a particular type of attention training that aims to maintain a balance between an alert and a relaxed state (Kubota et al., 2001; Wallace, 2008). The generated state may be particularly beneficial for sustaining attention for longer periods which, in turn, may be fundamental for the ability to overcome the automatic processing of distractions and interferences, even when they are internal and emotional. In this way, people can become less reactive to them and, consequently, may preserve more resources and more efficiently distribute them in a goal-oriented manner. Less automatic processing of distractions and more available resources may also facilitate interoceptive awareness, which may help maintain the relaxed state acquired, as well as to detect the body's responsiveness to emotional stimuli, facilitating the regulation of such response.

In cognitive terms it is known that attentional load can influence the susceptibility to process distractions. For example, people in a high demanding attentional condition, relative to low, showed a significantly reduced frequency of mind wandering - the normal tendency of the mind to fluctuate and distract (Forster \& Lavie, 2009). Hence, the more one allocates resources, the less one's mind wanders. Interestingly, mind wandering has been closely related to the default mode operation (Hasenkamp et al., 2012), which seems to be reduced in meditation (Pagnoni et al., 2008; Taylor et al., 2011). Specifically regarding emotion distraction, high attentional demand may not always modulate such interference (Vuilleumier, 2005, but see Pessoa et al., 2005), but meditation may provide a broader control by the combination of a better focus of attention along with a relaxing internal state. 


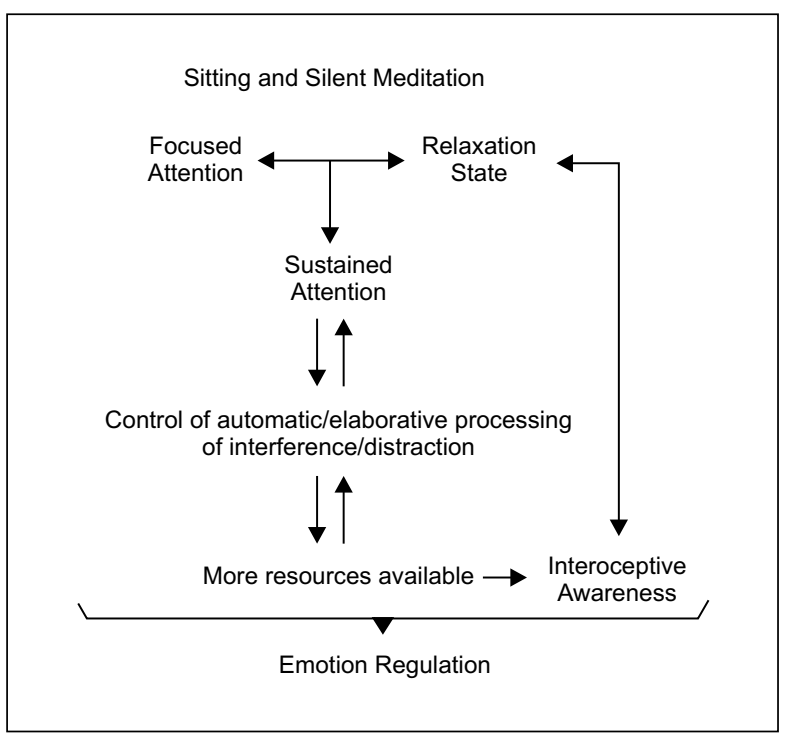

Figure 1. Diagram representing the hypothesized effect of meditation on emotion regulation based on the presented results.

\section{Final Considerations}

Despite the evidences, more studies evaluating the relationship between meditation and emotion regulation are clearly necessary. In particular, a paucity of studies has been observed including behavioral measures, studies investigating specifically focused attention meditation, as well as a great variability on the amount of practice time necessary to produce an effect. Also, it is important to carry out direct comparisons between meditation and other regulation strategies in order to better disentangle particular effects and neural networks. Likewise, it may be helpful to make direct and systematic comparisons of the impact of these strategies on different dependent variables such as emotional images, faces, films, sounds, etc. Importantly, one limitation of such studies is the extent to which the observed impact transfers to a more ecological context. Finally, although not being the scope of this article, meditation should also be considered regarding its role on the development or enhancement of positive emotions. To our knowledge, there is no review concerning this relationship in particular, which may contribute to a broader understanding of the importance of meditation for emotion regulation.

In summary, results indicate that meditation may constitute an effective strategy for negative emotion regulation with particularities that distinguish it from other strategies. We believe that this distinction does not imply that meditation is incompatible with other forms of regulation, but rather constitutes an alternative and additional resource for one's regulation repertoire. Moreover, similar to other strategies, meditation could be used as an antecedent or online strategy, and some also suggest it may be a form of implicit regulation, which is characterized by changes in emotion without conscious decision.

\section{References}

Aftanas, L., \& Golosheykin, S. (2005). Impact of regular meditation practice on EEG activity at rest and during evoked negative emotions. International Journal of Neuroscience, 115, 893-909. doi: $10.1080 / 00207450590897969$

Anderson, A. K. (2005). Affective influences on the attentional dynamics supporting awareness. Journal of Experimental Psychology: General, 134, 258-281. doi: 10.1037/00963445.134.2.258

Arch, J. J., \& Craske, M. G. (2006). Mechanisms of mindfulness: Emotion regulation following a focused breathing induction. Behavior Research and Therapy, 44, 1849-1858.

Baer, R. A. (Ed.). (2006). Mindfulness-based treatment approaches: Clinician's guide to evidence base and applications. San Diego: Academic Press.

Bishop, S. R., Lau, M., Shapiro, S., Carlson, L., Anderson, N. D., Carmody, J., ... Devins, G. (2004). Mindfulness: A proposed operational definition. Clinical Psychology: Science and Practice, $11,230-241$.

Brefczynski-Lewis, J. A., Lutz, A., Schaefer, H. S., Levinson, D. B., \& Davidson, R. J. (2007). Neural correlates of attentional expertise in long-term meditation practitioners. Proceedings of the National Academy of Sciences, 104, 11483-11488. doi: 10.1073/ pnas. 0606552104

Cahn, B. R., \& Polich, J. (2009). Meditation (Vipassana) and the P3a event-related brain potential. International Journal of Psychophysiology, 72, 51-60.

Chambers, R., Yee Lo, B. C., \& Allen, N. B. (2008). The impact of intensive mindfulness training on attentional control, cognitive style, and affect. Cognitive Therapy and Research, 32, 303-322.

Chiesa, A., \& Serretti, S. (2009). Mindfulness-based stress reduction for stress management in healthy people: A review and metaanalysis. The Journal of Alternative and Complementary Medicine, 15, 593-600. doi: $10.1089=$ acm.2008.0495

Dalgleish, T. (2003). Information processing approaches to emotion. In R. J. Davidson, K. R. Scherer \& H. H. Goldsmith (Eds.), Handbook of affective sciences (pp. 661-675). Oxford: Oxford University Press.

Damasio, A. R. (1996). O erro de descartes: emoção, razão e o cérebro humano. São Paulo: Companhia das Letras.

Danucalov, M. A. D., Simões, R. S., Kozasa, E. H., \& Leite, J. R. (2008). Cardiorespiratory and metabolic changes during yoga sessions: The effects of respiratory exercises and meditation practices. Applied Psychophysiology and Biofeedback, 33, 77-81.

Davidson, R. J. (2003). Seven sins in the study of emotion: Correctives from affective neuroscience. Brain and Cognition, 52, 129-132. doi: doi:10.1016/S0278-2626(03)00015-0

Davidson, R. J. (2010). Empirical explorations of mindfulness: Conceptual and methodological conundrums. Emotion, 10(1), 8-11. doi: 10.1037/a0018480

Davidson, R. J., Jackson, D. C., \& Kalin, N. H. (2000). Emotion, plasticity, context, and regulation: Perspectives from affective neuroscience. Psychological Bulletin, 126, 890-909.

Davidson, R. J., Kabat-Zinn, J., Schumacher, J., Rosenkranz, M., Muller, D., Santorelli, S. F., ... Sheridan, J. F. (2003). Alterations in brain and immune function produced by mindfulness meditation. Psychosomatic Medicine, 65, 564-570.

Delgado, M. R., Nearing, K. I., LeDoux, J. E., \& Phelps, E. A. (2008). Neural circuitry underlying the regulation of conditioned fear and its relation to extinction. Neuron, 59, 829-838. doi: 10.1016/j. neuron.2008.06.029

Diekhof, E. K., Geier, K., Falkai, P., \& Gruber, O. (2011). Fear is only as deep as the mind allows A coordinate-based meta-analysis of neuroimaging studies on the regulation of negative affect. NeuroImage, 58, 275-285. doi: 10.1016/j.neuroimage.2011.05.073

Ellsworth, P. C., \& Scherer, K. R. (2003). Appraisal processes in emotion. In R. J. Davidson, K. R. Scherer \& H. H. Goldsmith (Eds.), Handbook of affective sciences (pp. 572-595). Oxford: Oxford University Press.

Erisman, S. M., \& Roemer, L. (2010). A preliminary investigation of the effects of experimentally induced mindfulness on emotional responding to film clips Emotion, 10, 72-82. doi: 10.1037/ a0017162

Erthal, F. S., de Oliveira L., Mocaiber, I., Pereira, M. G., MachadoPinheiro, W., Volchan, E., \& Pessoa L. (2005). Load-dependent modulation of affective picture processing. Cognitive, Affective, \& Behavioral Neuroscience, 5, 388-395. 
Fang, C. Y., Reibel, D. K., Longacre, M. L., Rosenzweig, S., Campbell, D. E., \& Douglas, S. D. (2010). Enhanced psychosocial well-being following participation in a mindfulness-based stress reduction program is associated with increased natural killer cell activity. The Journal of Alternative and Complementary Medicine, 16, 531-538. doi: 10.1089/acm.2009.0018

Farb, N. A. S., Anderson, A. K., Mayberg, H., Bean, J., McKeon, D., \& Segal, Z. V. (2010). Minding one's emotions: Mindfulness training alters the neural expression of sadness. Emotion, 10, 25-33. doi: $10.1037 / \mathrm{a} 0017151$

Farb, N. A. S., Segal, Z. V., Mayberg, H., Bean, J., McKeon, D., Fatima, Z., ... Anderson, A. (2007). Attending to the present: mindfulness meditation reveals distinct neural modes of self-reference. Social Cognitive and Affective Neuroscience, 2, 313-322. doi: 10.1093/ scan/nsm030

Forster, S., \& Lavie, N. (2009). Harnessing the wandering mind: The role of perceptual load. Cognition, 111, 345-355. doi: 10.1016/j. cognition.2009.02.006

Goldin, P. R., \& Gross, J. J. (2010). Effects of mindfulness-based stress reduction (MBSR) on emotion regulation in social anxiety disorder. Emotion, 10, 83-91. doi: 10.1037/a0018441

Goldin, P. R., McRae, K., Ramel, W., \& Gross, J. J. (2008). The neural bases of emotion regulation: Reappraisal and suppression of negative emotion. Biological Psychiatry, 63, 577-586. doi: 10.1016/j.biopsych.2007.05.031

Gross, J. J. (1998). The emerging field of emotion regulation: An integrative review. Review of General Psychology, 2, 271-299.

Gross, J. J. (2002). Emotion regulation: affective, cognitive, and social consequences. Psychophysiology, 39, 281-291.

Gyurak, A., Gross, J. J., \& Etkin, A. (2011). Explicit and implicit emotion regulation: A dual-process framework. Cognition and Emotion, 25(3), 400-412. doi: 10.1080/02699931.2010.544160

Hakamata, Y., Lissek, S., Bar-Haim, Y., Britton, J. C., Fox, N. A., Leibenluft, E., ... Pine, D. S. (2010). Attention bias modification treatment: A meta-analysis toward the establishment of novel treatment for anxiety. Biological Psychiatry, 68, 982-990. doi: 10.1016/j.biopsych.2010.07.021

Hasenkamp, W., Wilson-Mendenhall, C. D., Duncan, E., \& Barsalou, L. W. (2012). Mind wandering and attention during focused meditation: A fine-grained temporal analysis of fluctuating cognitive states. NeuroImage, 59, 750-760. doi: 10.1016/j. neuroimage.2011.07.008

Hodsoll, S., Viding, E., \& Lavie, N. (2011). Attentional capture by irrelevant emotional distractor faces. Emotion, 11, 346-353. doi: 10.1037/a0022771

Jacobs, T. L., Epel, E. S., Lin, J., Blackburn, E. H., Wolkowitz, O. M., Bridwell, D. A., ... MacLean, K. A. (2011). Intensive meditation training, immune cell telomerase activity, and psychological mediators. Psychoneuroendocrinology, 36, 664-681. doi: 10.1016/j.psyneuen.2010.09.010

Jain, S., Shapiro, S. L., Swanick, S., Roesch, S. C., Mills, P. J., Bell, I., Schwartz, G. (2007). A randomized controlled trial of mindfulness meditation versus relaxation training: Effects on distress, positive states of mind, rumination and distraction. Annals of Behavioral Medicine, 33, 11-21.

Jha, A. P., Krompinger, J., \& Baime, M. (2007). Mindfulness training modifies subsystems of attention. Cognitive, Affective, \& Behavioral Neuroscience, 7, 109-119.

Jha, A. P., Stanley, E. A., Kiyonaga, A., Wong, L., \& Gelfand, L. (2010). Examining the protective effects of mindfulness training on working memory capacity and affective experience. Emotion, 10, 54-64. doi: 10.1037/a0018438

Johnson, D. R. (2009). Emotional attention set-shifting and its relationship to anxiety and emotion regulation. Emotion, 9, 681690. doi: $10.1037 / \mathrm{a} 0017095$

Khalsa, S., Rudrauf, D., Damasio, A. R., Davidson, R. J., Lutz, A., \& Tranel, D. (2008). Interoceptive awareness in experienced meditators. Psychophysiology, 45, 671-677. doi: 10.1111/j.14698986.2008.00666.x.

Kingston, J., Chadwick, P., Meron, D., \& Skinner, T. C. (2007). A pilot randomized control trial investigating the effect of mindfulness practice on pain tolerance, psychological well-being, and physiological activity. Journal of Psychosomatic Research, 62, 297-300. doi: 10.1016/j.jpsychores.2006.10.007

Klatt, M. D., Buckworth, J., \& Malarkey, W. B. (2009). Effects of low-dose mindfulness-based stress reduction (MBSR-ld) on working adults. Health Education \& Behavior, 36, 601-614. doi: $10.1177 / 1090198108317627$
Kompus, K., Hugdahl, K., Öhman, A., Marklund, P., \& Nyberg, L. (2009). Distinct control networks for cognition and emotion in the prefrontal cortex. Neuroscience Letters, 467, 76-80. doi: 10.1016/j. neulet.2009.10.005

Kubota, Y., Sato, W., Toichi, M., Murai, T., Okada, T., Hayashi, A., Sengoku, A. (2001). Frontal midline theta rhythm is correlated with cardiac autonomic activities during the performance of an attention demanding meditation procedure. Cognitive Brain Research, 11, 281-287.

Kumar, S., Nagendra, H. R., Naveen, K. V., Manjunath, N. K., \& Telles, S. (2010). Brainstem auditory evoked potentials in two meditative mental states. International Journal of Yoga, 3, 37-41.

Lavie, N., Ro, T., \& Russell, C. (2003). The role of perceptual load in processing distractor faces. Psychological Science, 14, 510-515. doi: $10.1111 / 1467-9280.03453$

Leite, J. R., Leite, F., Ornellas, M., Amemiya, T. M., Almedia, A. A. F., Dias, A. A., ... Little, S. (2010). Effect of progressive self-focus meditation on attention, anxiety, and depression scores. Perceptual and Motor Skills, 110, 840-848. doi: 10.2466/PMS.110.3.840-848

Lobo, I., Oliveira, L., David, I. A., Pereira, M. G., Volchan, E., RochaRego, V., ... Mocaiber, I. (2011). The neurobiology of posttraumatic stress disorder: Dysfunction in the prefrontal-amygdala circuit? Psychology \& Neuroscience, 4, 191-203.doi: 10.3922/ j.psns.2011.2.004

Lutz, A., Dunne, J. D., \& Davidson, R. J. (2007). Meditation and the neuroscience of consciousness: An introduction. In P. Zelazo, M. Moscovitch \& E. Thompson (Eds.), Cambridge handbook of consciousness (pp. 499-554). New York: Cambridge University Press.

Lutz, A., Slagter, H. A., Dunne, J. D., \& Davidson, R. J. (2008). Attention regulation and monitoring in meditation. Trends in Cognitive Sciences, 12, 163-169. doi: 10.1016/j.tics.2008.01.005

MacLean, K. A., Ferrer, E., Aichele, S. R., Bridwell, D. A., Zanesco, A. P., Jacobs, T. L., ... Saron, C. D. (2010). Intensive meditation training improves perceptual discrimination and sustained attention. Psychological Science. doi: 10.1177/0956797610371339

McRae, K., Hughes, B., Chopra, S., Gabrieli, J. D. E., Gross, J. J., \& Ochsner, K. N. (2010). The neural bases of distraction and reappraisal. Journal of Cognitive Neuroscience, 22, 248-262.

Mitchell, D. G. V., Nakic, M., Fridberg, D., Kamel, N., Pine, D. S., \& Blair, R. J. R. (2007). The impact of processing load on emotion. Neurolmage, 34, 1299-1309. doi: 10.1016/j. neuroimage.2006.10.012

Mocaiber, I., Pereira, M. G., Erthal, F. S., Figueira, I., MachadoPinheiro, V., Cagy, M., ... Oliveira, L. (2009). Regulation of negative emotions in high trait anxious individuals: An ERP study. Psychology \& Neuroscience, 2, 211-217. doi: 10.3922/j. psns.2009.2.014

Ochsner, K. N., Bunge, S. A., Gross, J. J., \& Gabrieli, J. D. E. (2002). Rethinking feelings: An fMRI study of the cognitive regulation of emotion. Journal of Cognitive Neuroscience, 14, 1215-1229. doi: 10.1162/089892902760807212

Ochsner, K. N., \& Gross, J. J. (2005). The cognitive control of emotion. Trends in Cognitive Sciences, 9, 242-249. doi: 10.1016/j. tics.2005.03.010

Ochsner, K. N., Ray, R. D., Cooper, J. C., Robertson, E. R., Chopra, S., Gabrieli, J. D. E., Gross, J. J. (2004). For better or for worse: neural systems supporting the cognitive down- and up-regulation of negative emotion. NeuroImage, 23, 483-499. doi: 10.1016/j. neuroimage.2004.06.030

Ochsner, K. N., Ray, R. R., Hughes, B., McRae, K., Cooper, J. C., Weber, J., ... Gross, J. J. (2009). Bottom-up and top-down processes in emotion generation: Common and distinct neural mechanisms. Psychological Science, 20, 1322-1331. doi: 10.1111/j.14679280.2009.02459.x

Ortner, C. N. M., Kilner, S. J., \& Zelazo, P. D. (2007). Mindfulness meditation and reduced emotional interference on a cognitive task. Motivation and Emotion, 31, 271-283.

Pagnoni, G., Cekic, M., \& Guo, Y. (2008). Thinking about notthinking: Neural correlates of conceptual processing during Zen meditation. PloS ONE, 3, e3083. Retrieved on 03/02/2010, from www.plosone.org doi:doi:10.1371/journal.pone. 0003083

Panksepp, J. (2003). At the interface of the affective, behavioral, and cognitive neurosciences: Decoding the emotional feelings of the brain. Brain and Cognition, 52, 4-14. doi: 10.1016/S0278-2626, 00003-4

Perlman, D. M., Salomons, T. V., Davidson, R. J., \& Lutz, A. (2010). Differential effects on pain intensity and unpleasantness of 
two meditation practices. Emotion, 10, 65-71. doi: 10.1037/ a0018440

Pessoa, L. (2008). On the relationship between emotion and cognition. Nature Reviews: Neuroscience, 9, 148-158. doi: 10.1038/ nrn2317

Pessoa, L., Padmala, S., \& Morland, T. (2005). Fate of unattended fearful faces in the amygdala is determined by both attentional resources and cognitive modulation. NeuroImage, 28, 249-255. doi: doi:10.1016/j.neuroimage.2005.05.048

Phelps, E. A. (2006). Emotion and cognition: Insights from studies of the human amygdala. Annual Review of Psychology, 57, 27-53. doi: 10.1146/annurev.psych.56.091103.070234

Ray, R. D., Ochsner, K. N., Cooper, J. C., Robertson, E. R., Gabrieli, J. D., \& Gross, J. J. (2005). Individual differences in trait rumination and the neural systems supporting cognitive reappraisal. Cognitive, Affective and Behavioral Neuroscience, 5, 156-168.

Sahdra, B. K., MacLean, K. A., Ferrer, E., Shaver, P. R., Rosenberg, E. L., Jacobs, T. L., ,.. Saron, C. D. (2011). Enhanced response inhibition during intensive meditation training predicts improvements in selfreported adaptive socioemotional functioning. Emotion, 11, 299312. doi: $10.1037 / \mathrm{a} 0022764$

Scherer, K. R. (2003). Introduction: Cognitive components of emotion. In R. J. Davidson, K. R. Scherer \& H. H. Goldsmith (Eds.), Handbook of affective sciences (pp. 563-571). Oxford: Oxford University Press.

Schroevers, M. J., \& Brandsma, R. (2010). Is learning mindfulness associated with improved affect after mindfulness-based cognitive therapy? British Journal of Psychology, 101, 95-107. doi: 10.13 8/000712609X HI9S

Shapiro, S. L., Oman, D., Thoresen, C. E., Plante, T. G., \& Flinders, T. (2008). Cultivating mindfulness: Effects on well-being. Journal of Clinical Psychology, 64, 840-862.

Sheppes, G., Catran, E., \& Meiran, N. (2009). Reappraisal (but not distraction) is going to make you sweat: Physiological evidence for self-control effort. International Journal of Psychophysiology, 71, 91-96. doi: 10.1016/j.ijpsycho.2008.06.006

Sheppes, G., \& Meiran, N. (2007). Better late than never? On the dynamics of online regulation of sadness using distraction and cognitive reappraisal Personality and Social Psychological Bulletin, 33, 1518-1532. doi: 10.1177/0146167207305537

Silvert, L., Lepsien, J., Fragopanagos, N., Goolsby, B., Kiss, M., Taylor, J. G., ... Nobrea, A. C. (2007). Influence of attentional demands on the processing of emotional facial expressions in the amygdala. NeuroImage, 38, 357-366. doi: 10.1016/j.neuroimage.2007.07.023

Slagter, H. A., Lutz, A., Greischar, L. L., Francis, A. D., Nieuwenhuis, S., Davis, J. M., Davidson, R. J. (2007). Mental training affects distribution of limited brain resources. PLoS Biology, 5. Retrieved on 15/06/2008 from http://www.plosbiology.org/article/ info\%3Adoi\%2F10.1371\%2Fjournal.pbio.0050138

Stein, T., Peelen, M. V., Funk, J., \& Seidl, K. N. (2007). The fearfulface advantage is modulated by task demands: Evidence from the attentional blink. Emotion, 10, 136-140. doi: 10.1037/a0017814

Sze, J. A., Gyurak, A., Yuan, J. W., \& Levenson, R. W. (2010). Coherence between emotional experience and physiology: Does body awareness training have an impact? Emotion, 10, 803-814. doi: $10.1037 / \mathrm{a} 0020146$

Takahashi, T., Murata, T., Hamada, T., Omori, M., Kosaka, H., Kikushi, M., ... Wada, Y. (2005). Changes in EEG and autonomic nervous activity during meditation and their association with personality traits. International Journal of Psychophysiology, 55, 199-207.

Tang, Y., Ma, Y., Fan, Y., Feng, H., Wang, J., Feng, S., ... Fan, M. (2009). Central and autonomic nervous system interaction is altered by short-term meditation. Proceedings of the National Academy of Sciences. Retrieved in 07/08/2009, from http://www. pnas.org/content $/ 106 / 22 / 8865$.full? sid $=81 \mathrm{c} 57 \mathrm{e} 1 \mathrm{c}-1 \mathrm{c} 7 \mathrm{a}-4 \mathrm{ce} 0$ 8c73-bdd9b7914538

Tang, Y., Ma, Y., Wang, J., Fan, Y., Feng, S., Lu, Q., ... Posner, M. I. (2007). Short-term meditation training improves attention and self-regulation. Proceedings of the National Academy of Sciences, 104, 17152-17156.
Tang, Y., \& Posner, M. I. (2009). Attention training and attention state training. Trends in Cognitive Sciences, 13, 222-227.

Taylor, V. A., Grant, J., Daneault, V., Scavone, G., Breton, E., Vidal, S., ... Beauregard, M. (2011). Impact of mindfulness on the neural responses to emotional pictures in experienced and beginner meditators. NeuroImage, 57, 1524-1533. doi: 10.1016/j. neuroimage.2011.06.001

Teasdale, J. D. (1999). Metacognition, mindfulnes, and the modification of mood disorders. Clinical Psychology and Psychotherapy, 6, 146-155.

Telles, S., Mohapatra, R. S., \& Naveen, K. V. (2005). Heart rate variability spectrum during Vipassana mindfulness meditation. Journal of Indian Psychology, 23, 1-5.

Telles, S., Naveen, K. V., \& Balkrishna, A. (2010). Meditation and attention: A comment on a recent article. Perceptual and Motor Skills, 111, 1-3. doi: 10.2466/02.04.20.22.PMS.111.6

Thayer, J. F., \& Lane, R. D. (2000). A model of neurovisceral integration in emotion regulation and dysregulation. Journal of Affective Disorders, 61, 201-216. doi: doi:10.1016/S01650327(00)00338-4

Thiruchselvam, R., Blechert, J., Sheppes, G., Rydstrom, A., \& Gross, J. J. (2011). The temporal dynamics of emotion regulation: An EEG study of distraction and reappraisal. Biological Psychology, 87, 84-92. doi: 10.1016/j.biopsycho.2011.02.009

Urry, H. L. (2010). Seeing, thinking, and feeling: Emotion-regulating effects of gaze-directed cognitive reappraisal. Emotion, 10, 125135. doi: $10.1037 / \mathrm{a} 0017434$

van den Hurk, P. A. M., Janssen, B. H., Giommi, F. G., Barendregt, H. P., \& Gielen, S. C. (2010). Mindfulness meditation associated with alterations in bottom-up processing: Psychophysiological evidence for reduced reactivity. International Journal of Psychophysiology, 78, 151-157. doi: 10.1016/j.ijpsycho.2010.07.002

Van Overwalle, F. (2008). Social cognition and the brain: A metaanalysis. Human Brain Mapping, 9999, NA.

van Reekum, C. M., Johnstone, T., Urry, H. L., Thurow, M. E., Schaefer, H. S., Alexander, A. L., \& Davison, R. J. (2007). Gaze fixations predict brain activation during the voluntary regulation of picture-induced negative affect. NeuroImage, 36, 1041-1055. doi: 10.1016/j.neuroimage.2007.03.052

Vuilleumier, P. (2005). How brains beware: neural mechanisms of emotional attention. Trends in Cognitive Sciences, 9, 585-594. doi: 10.1016/j.tics.2005.10.011

Vuilleumier, P., Sagiv, N., Hazeltine, E., Poldrack, R. A., Swick, D., Rafal, R. D., \& Gabrieli, J. D. E. (2001). Neural fate of seen and unseen faces in visuospatial neglect: A combined event-related functional MRI and event-related potential study. Proceedings of the National Academy of Sciences, 98, 3495-3500. doi: 10.1073/ pnas.051436898

Wadlinger, H. A., \& Isaacowitz, D. M. (2008). Looking happy: The experimental manipulation of a positive visual attention bias. Emotion, 8(121-126).

Wadlinger, H. A., \& Isaacowitz, D. M. (2011). Fixing our focus: Training attention to regulate emotion. Personality and Social Psychology Review, 15, 75-102. doi: 10.1177/1088868310365565

Wallace, B. A. (2008). A revolução da atenção: Revelando o poder da mente focada. Petrópolis: Vozes.

Wallace, B. A., \& Shapiro, S. L. (2006). Mental balance and well-being: Building bridges between buddhism and western psychology. American Psychologist, 61, 690-701.

Walsh, R., \& Shapiro, S. L. (2006). The meeting of meditative disciplines and western psychology: A mutually enriching dialogue. American Psychologist, 61, 227-239.

Wells, A. (2006). Detached mindfulness in cognitive therapy: A metacognitive analysis and ten techniques. Journal of RationalEmotive \& Cognitive-Behavior Therapy, 23, 337-355.

Wells, A. (2009). Metacognitive therapy for anxiety and depression. New York: The Guilford Press.

Zeidan, F., Johnson, S. K., Diamond, B. J., David, Z., \& Goolkasian, P. (2010). Mindfulness meditation improves cognition: Evidence of brief mental training. Consciousness and Cognition. doi: 10.1016/j.concog.2010.03.014. 